\title{
Microcirculatory Patterns in Adult Rat Cerebral Hypophysis: A Scanning Electron Microscope Study of Replicated Specimens*
}

\author{
Takuro Murakami ${ }^{1}$, Tsuyoshi MiYake ${ }^{1,2}$, Aiji Ohtsuka ${ }^{1}$, Akio KIKUTa ${ }^{1}$ and Takehito Taguchi \\ Departments of Anatomy ${ }^{1}$ and Internal Medicine, ${ }^{2}$ Okayama University School of Medicine, Okayama, Japan
}

Received June 16, 1993

\begin{abstract}
Summary. The blood vascular bed of the cerebral hypophysis in the adult rat was replicated completely or incompletely by arterial injection of different amounts of methacrylate resin, to be observed with a scanning electron microscope.

Complete replication confirmed our previous findings (Murakami et al., 1987) on the distribution and structure of the vascular beds in and around the hypophysis of the rat. One long major and several minor portal routes (vide infra) were reproduced sufficiently together with the systemic veins of the posterior lobe.

Incomplete replication demonstrated that resin flows: 1) via the long portal vessels from the median eminence and neural stalk to the anterior lobe; 2 ) via the accessory long portal vessels from the subependyma to the anterior lobe; 3 ) via the short portal vessels from the posterior lobe to the anterior lobe; 4) via the neurointermedial portal vessels from the posterior lobe to the intermediate lobe; 5) via the intermedio-distal portal vessels from the intermediate lobe to the anterior lobe; and 6) via the tuberal portal vessels from the tuberal lobe to the anterior lobe.

Incomplete replication also demonstrated that resin in the median eminence and neural stalk is drained preferentially into the anterior lobe via the long portal vessels, and that resin in the posterior lobe is drained mainly into the systemic veins. We were unable to demonstrate a retrograde resin flow from the anterior lobe to the median eminence, subependyma, neural stalk, intermediate lobe and posterior lobe, nor an ascending resin flow from the posterior lobe to the median eminence and subependyma. Also failing to be noted were an ascending resin flow from the hypophysis to the hypothalamus and a descending resin flow from hypothalamus to the hypophysis.
\end{abstract}

Complete injection of low viscosity resin through arteries (complete arterial resin injection) reproduces the whole extent of blood vascular beds, including thick venous portions (MURAKAMI, 1971; MURAKAMI et al., 1973). Injection of small amounts of resin through arteries (incomplete arterial resin injection) tends to reproduce the arterially connected aspect of the vascular bed, its venular and venous aspect remaining unfilled (MURAKAMI et al., 1983; 1987). A combination of both complete and incomplete injection methods thus allows a precise analysis of the fine vascular connections as well as the microvascular patterns (microvasculatory directions) of an organ or tissue (Murakami, 1971; MuraKami et al., 1983, 1987; MrYAKE et al., 1992).

This paper demonstrates findings by scanning electron microscopy of cast specimens prepared by such a combined method of resin injections. The rat hypophysis forms the object of the present study, from an interest to reveal the precise microcirculatory patterns of the portal vessels in the hypophysis (MURAKAMI, 1975a, b, 1992; MURAKAMI et al., 1985, 1987). The findings on the vascular beds of the hypothalamus are also included.

\section{MATERIALS AND METHODS}

Adult male Wistar rats weighing 250-260 g were anesthetized with ethyl ether, and their ascending aorta was cannulated through the left ventricle after ligation of the thoracic aorta just below the origin of the left subclavian artery. The animals were then irrigated through the cannulated aorta with Ringer solution

${ }^{*}$ This work was supported in part by a grant from the Ministry of Education, Science and Culture, Japan. 
$(30 \mathrm{ml})$, and perfused through this aorta with $0.1,0.2$, $0.3,0.4,0.5,1.0,2.5,5.0,7.5,10.0,12.5,15.0,20.0,25.0$, 30.0 or $35.0 \mathrm{ml}$ of a semi-polymerized and diluted methacrylate casting medium with a low viscosity corresponding to that of blood (MURAKAMI, 1971; MURAKAMI et al., 1973; MIYAKE et al., 1992; MURAKAMI and FujiTA, 1992) at an injection pressure of $100-120$ $\mathrm{mmHg}$.

The resin-injected animals were placed in a hot water bath (MURAKAMI, 1971; MURAKAMI et al., 1973) or treated with a microwave processor (MURAKAMI et al., 1992), and their hypophysis was isolated together with the associated tissue elements. These isolated organs were immersed in a hot $10 \% \mathrm{NaOH}$ solution and washed in water (MURAKAMI, 1971). This series of maceration and washing was repeated several times.

The blood vascular casts of the hypophysis and associated cephalic tissues thus prepared were airdried or freeze-dried, exposed to osmium vapor (MURAKAMI et al., 1973), coated with gold, and observed with a scanning electron microscope (S-2300 or HHS-2R, Hitachi) using an acceleration voltage of $5 \mathrm{kV}$. Some casts were freeze-cut with razor blades prior to the scanning observation (MURAKAMI et al., 1987).

\section{RESULTS}

\section{Complete injections}

Injections of $20.0 \mathrm{ml}$ or more low viscosity methacrylate resin into the ascending aorta after ligation of the thoracic aorta thoroughly reproduced the hypophyseal blood vascular bed of adult rats weighing

Table 1. Abbreviations in Figures 1-13

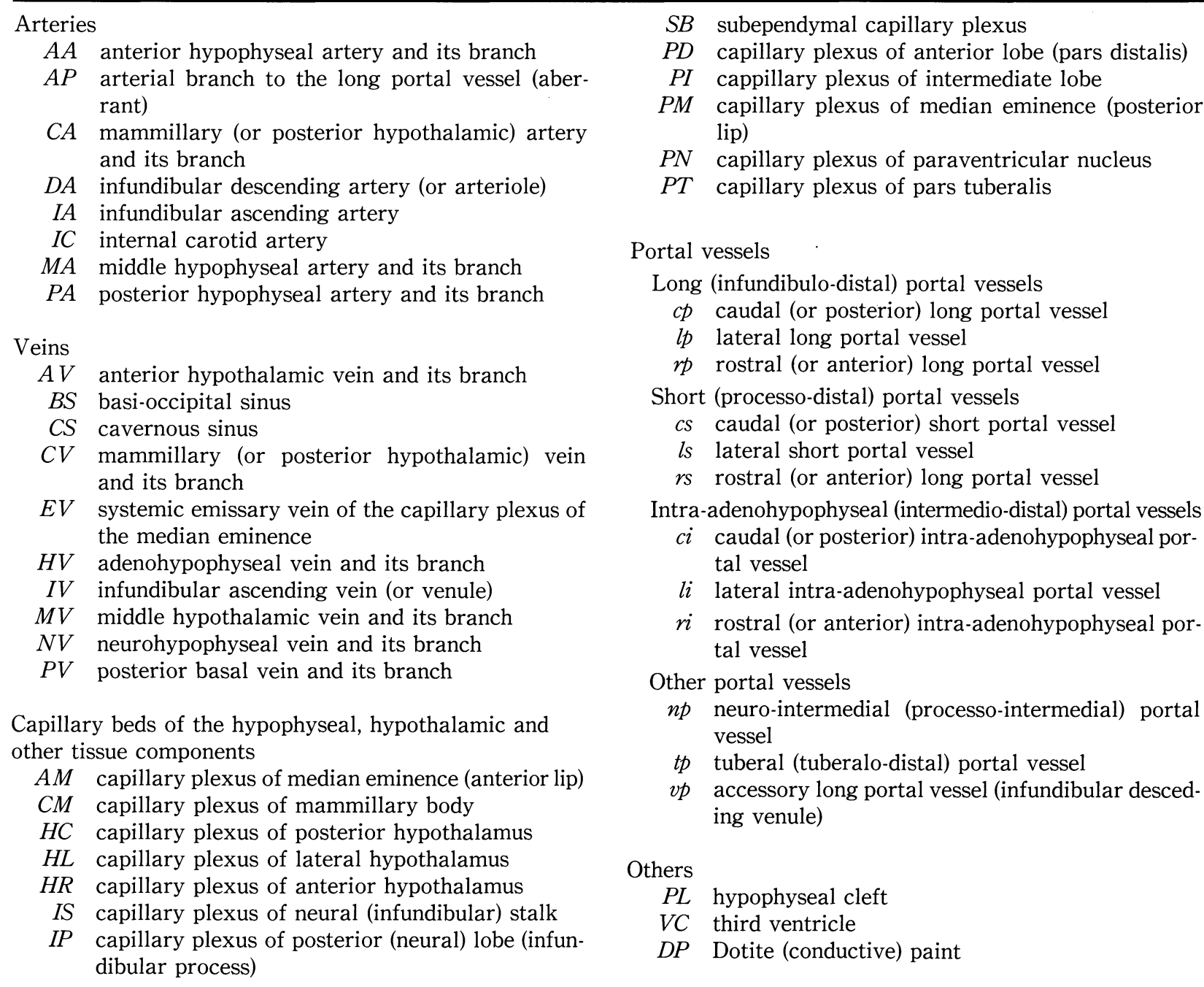




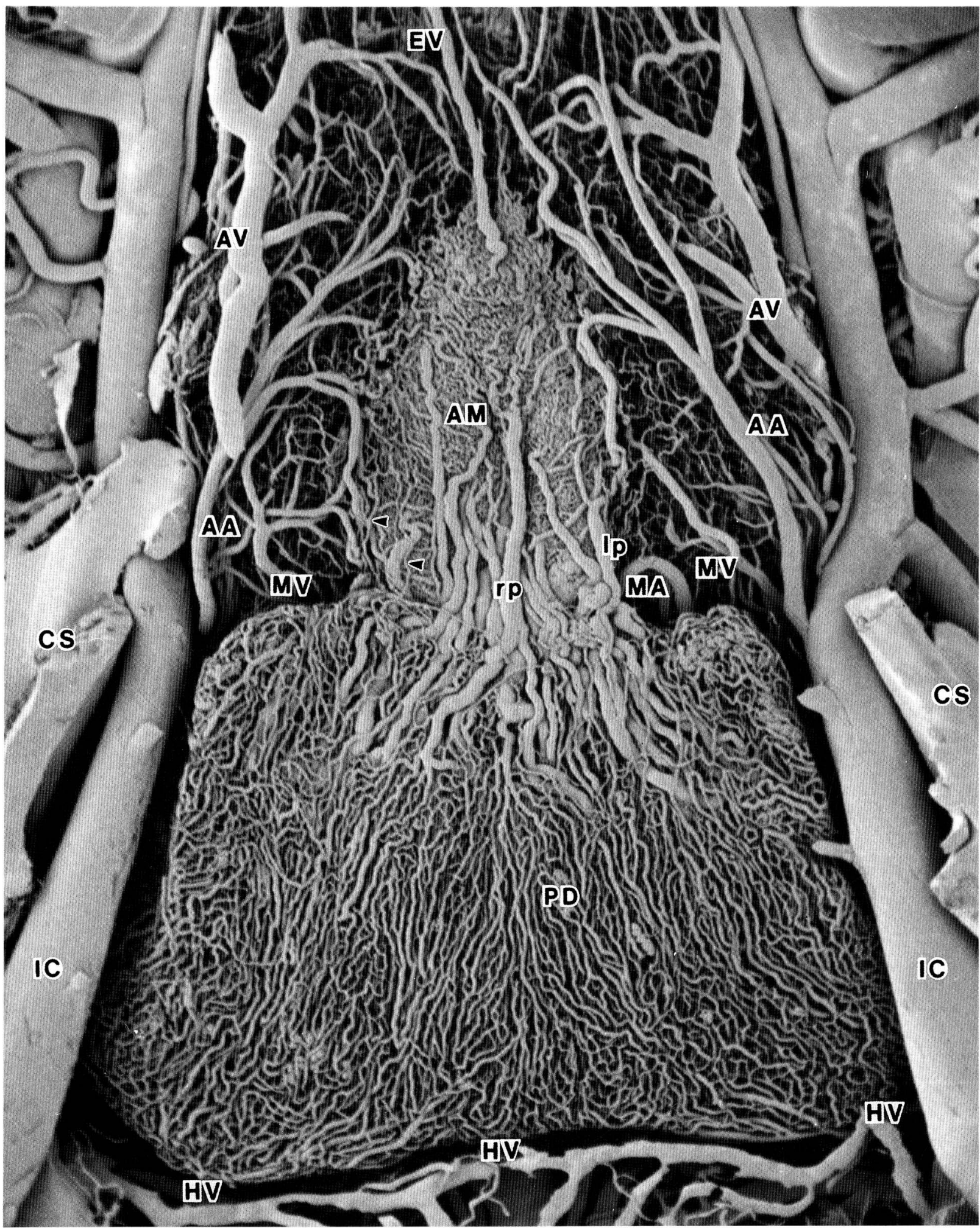

Fig. 1. A scanning electron micrograph of completely replicated blood vascular beds of the adult rat hypophysis and hypothalamus (ventral view). Arrowheads indicate the tuberal portal vessels. For abbreviations, see Table $1 . \times 40$ 
EF,

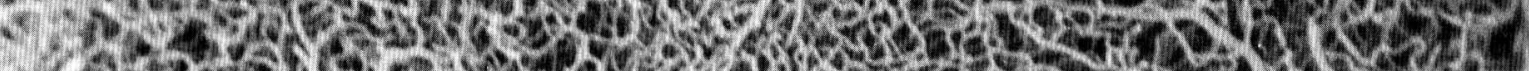

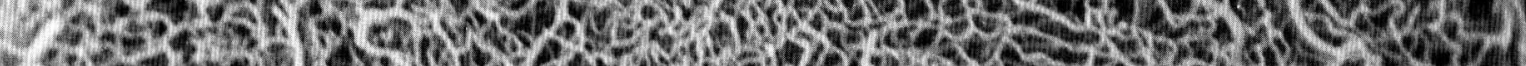

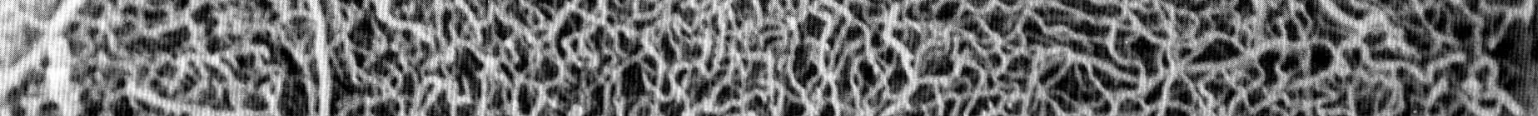

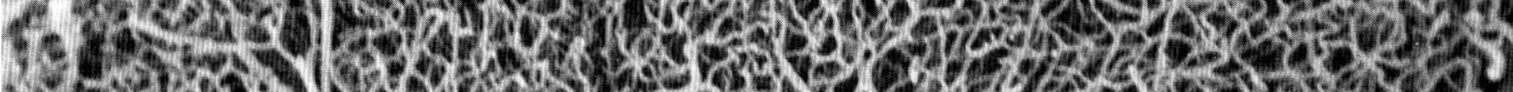

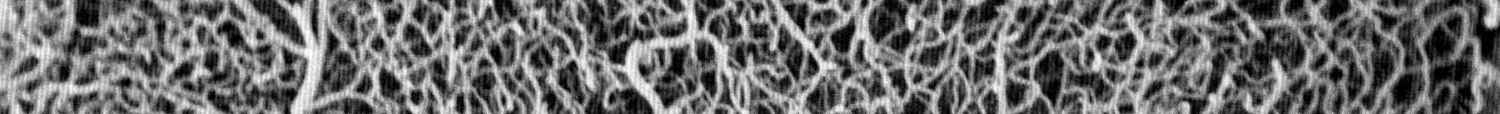

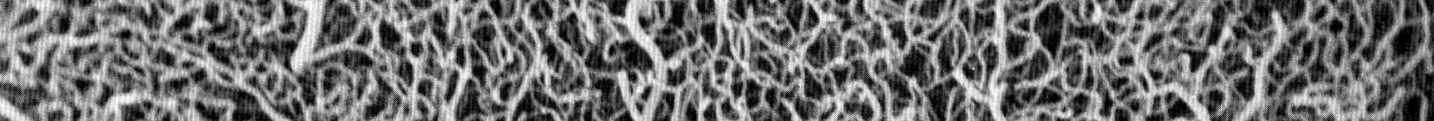

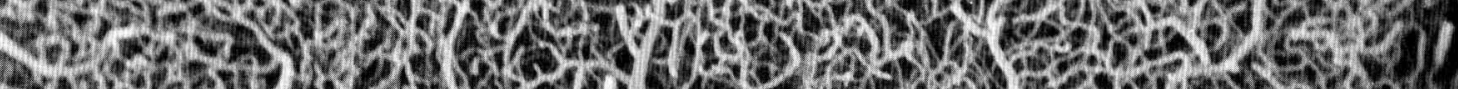
If - T.

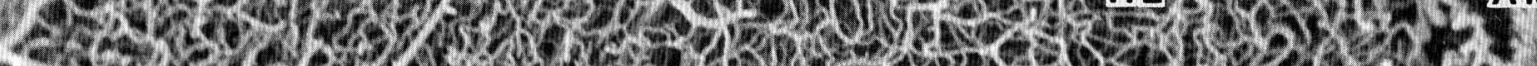
cto-

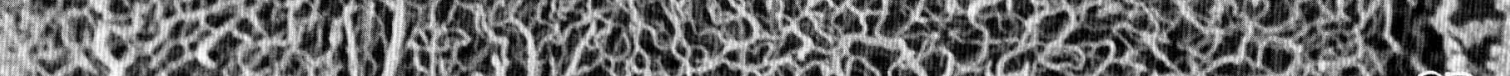
w.

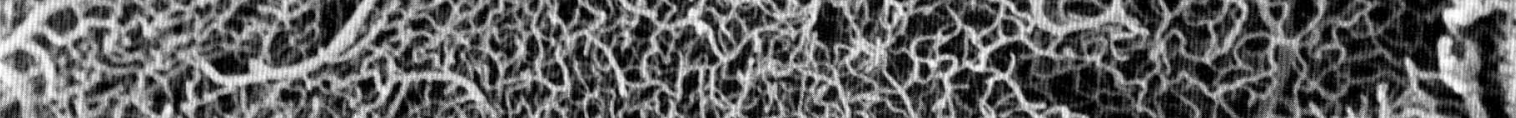
4.5.

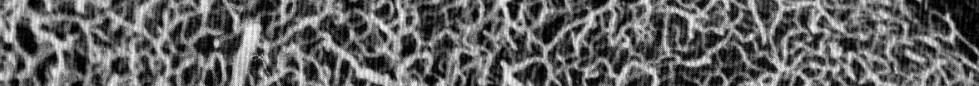
-

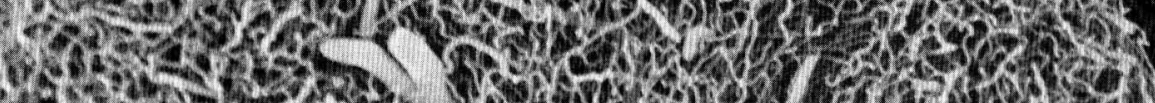
- 2 a 13. 2 if

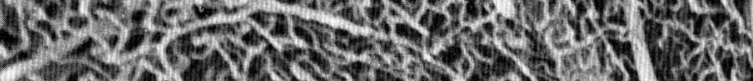
Ys.

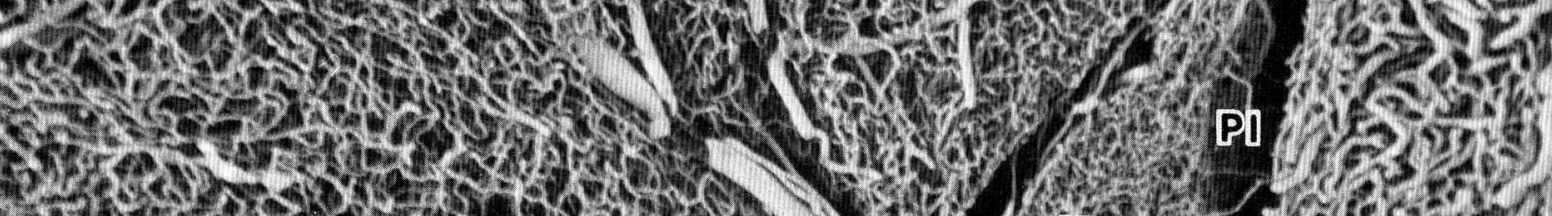

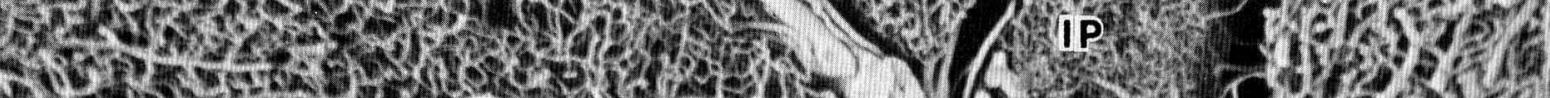
5 -

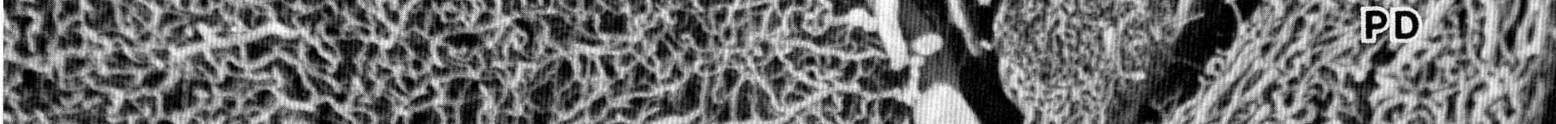

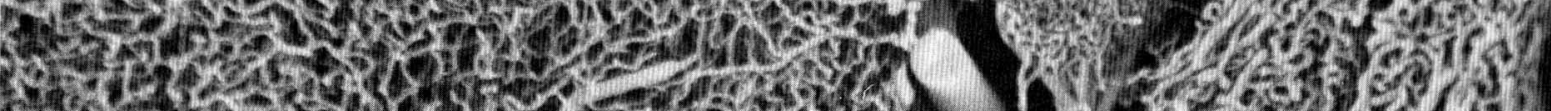

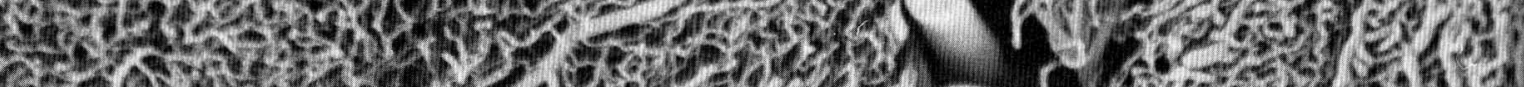

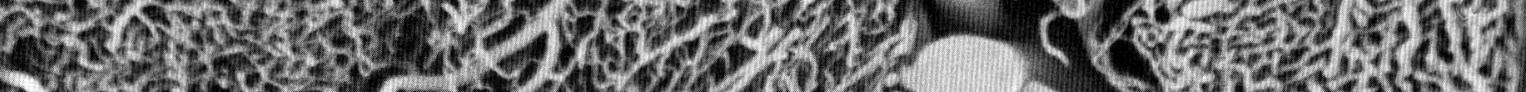
2.3. W.

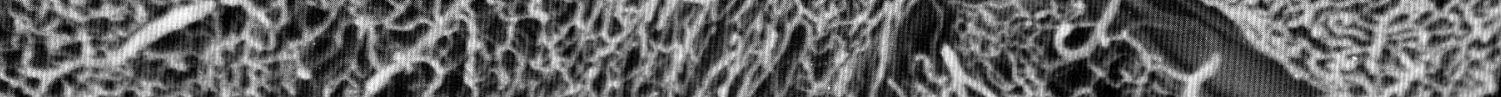

Fig. 2 Completely replicated and sagittally freeze-cut blood vascular beds of the adult rat hypophysis and hypothalamus. A part of this figure is shown elsewhere (Fig. 5, MurakAmI et al., 1987). For abbreviations, see Table $1 . \times 40$ 


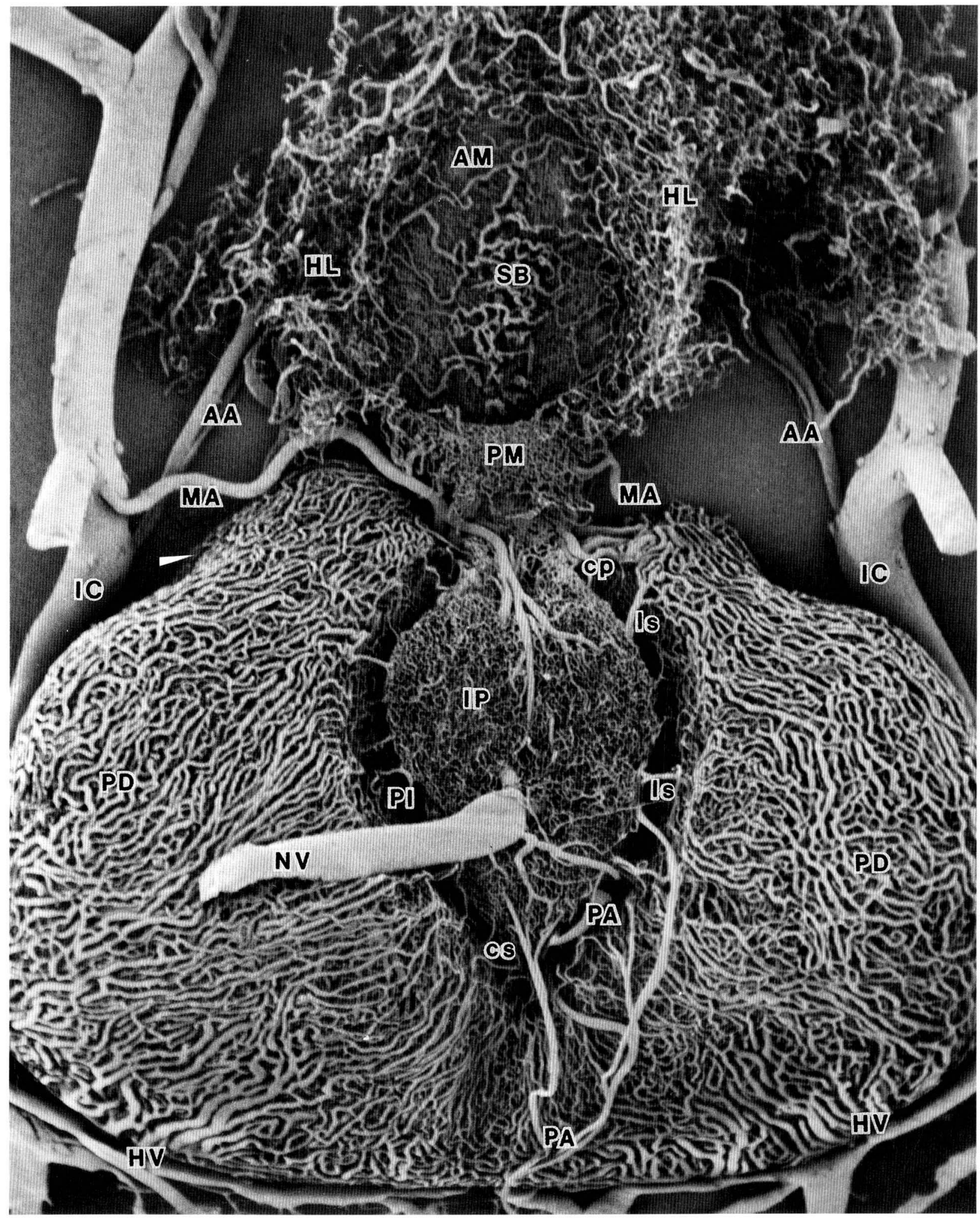

Fig. 3. Dorsal view of completely replicated and isolated blood vascular beds of the adult rat hypophysis and hypothalamus. For abbreviations, see Table $1 . \times 40$ 

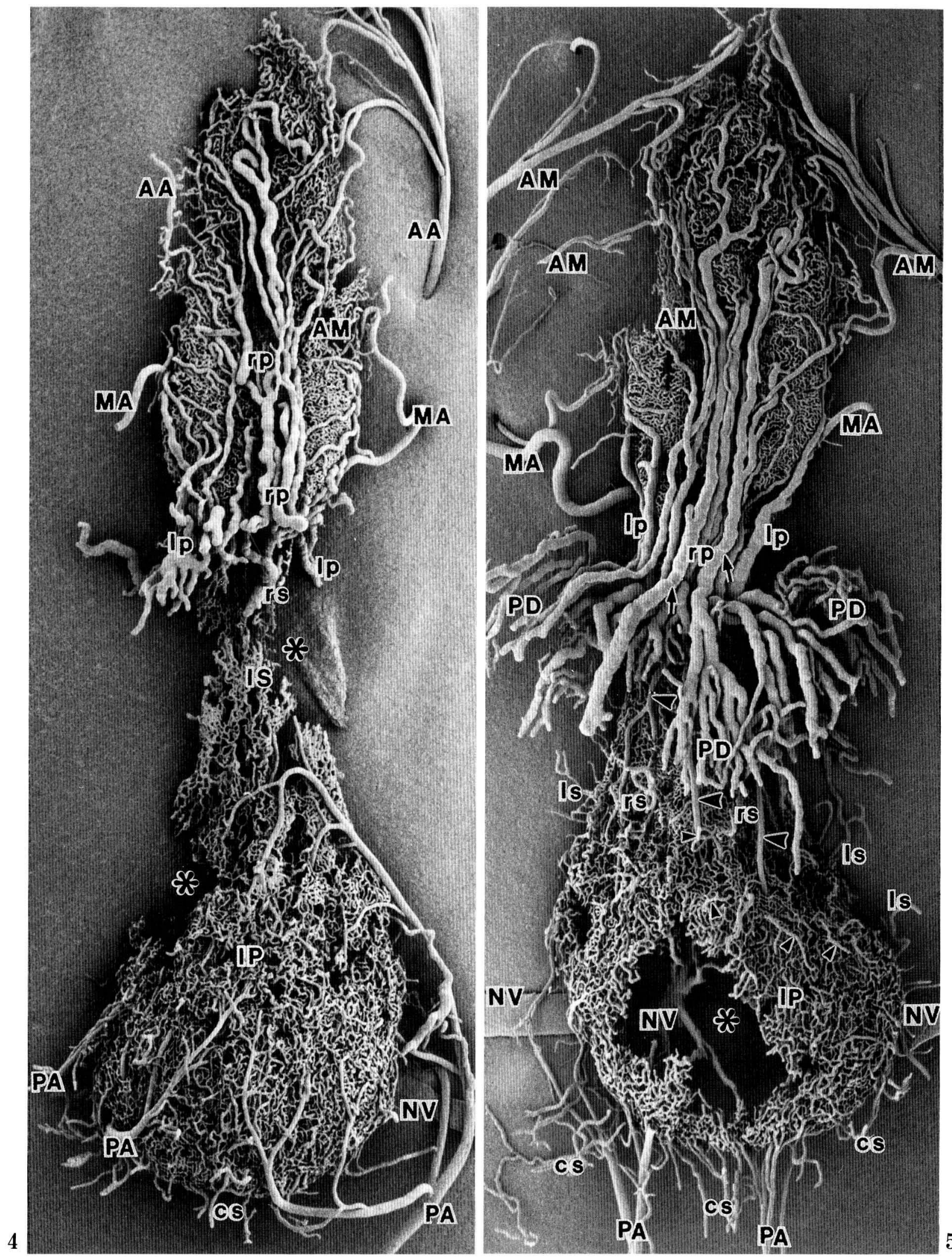

Figs. 4 and 5. Legends on the opposite page. 
$250-260 \mathrm{~g}$. However, injections of $30.0 \mathrm{ml}$ or more resin were required for a thorough reproduction of the blood vascular beds of other cephalic organs, including the hypothalamus, of adult rats at this body weight (Figs. 1-3) (see below).

Scanning electron microscopy of these completely replicated specimens showed that the adult rat hypophyseal blood vascular bed consists of the capillary plexuses of the third ventricular subependyma, median eminence (infundibulum), infundibular (neural) stalk, infundibular process (posterior or neural lobe), pars tuberalis (tuberal lobe), pars intermedia (intermediate lobe), and pars distalis (anterior lobe) (Figs. 1-3). It also showed that this bed comprises 1) fifteen to twenty long (infundibulo-distal) portal vessels connecting the capillary plexuses of the median eminence and neural stalk with the plexus of anterior lobe, 2) four to eight accessory long (subependymodistal) portal vessels (infundibular descending venules) connecting the capillary plexus of the third ventricular subependyma with the long portal vessels, 3) fourteen to twenty-two short (processo-distal) portal vessels connecting the capillary plexus of the posterior lobe with that of the anterior lobe, 4) fifteen to twenty-one neuro-intermedial (processo-intermedial) portal vessels connecting the capillary plexus of the posterior lobe with that of the intermediate lobe, 5) ten to fifteen intra-adenohypophyseal (intermediodistal) portal vessels connecting the capillary plexus of the intermediate lobe with that of the anterior lobe, and 6) two to six tuberal (tuberalo-distal) portal vessels connecting the capillary plexus of the pars tuberalis with that of the anterior lobe (Figs. 1-3). It further confirmed that the long portal vessels are markedly thicker in size than the other ones, and also that the long route (capillary plexuses of the median eminence and neural stalk, long portal vessels, and capillary plexus of the anterior lobe) occupies the main part of the portal system, while other routes only occupy a small part (Figs. 1-3).

Complete replication, moreover, showed that the capillary plexus of the posterior lobe issues, at its dorso-caudal aspect, one or more thick systemic veins (neurohypophyseal veins) (Figs. 3), and that the anterior lobe emits many small systemic or emissary veins (adenohypophyseal veins) at its ventro-posterior and latero-posterior ends. Furthermore, complete replication revealed that the subependymal capillary plexus issues several systemic veins (infundibular ascending veins or venules) continuous with the hypothalamic veins, and that the capillary plexus of the median eminence occasionally emits a few systemic veins or venules continuous with the hypothalamic veins (Fig. $1)$.

As the details of these findings have been dealt with elsewhere (MURAKAMI, 1975a, 1992; MURAKAMI et al., $1985,1987)$, they will be omitted in the present paper. Only the basic findings are schematically illustrated in Figure 13.

\section{Incomplete injections}

Injection of $15.0 \mathrm{ml}$ or less resin into the ascending aorta after ligation of the thoracic aorta incompletely replicated the hypophyseal blood vascular bed in adult rats weighing 250-260 g (Figs. 4-12).

With an injection of $0.1 \mathrm{ml}$ resin, only the original segments of the anterior, middle and posterior hypophyseal arteries were reproduced together with their parent arteries. With $0.2 \mathrm{ml}$ resin, the capillary plexus of the median eminence was partially reproduced, but not the respective plexuses of the neural stalk and posterior lobe. With $0.3 \mathrm{ml}$ resin injection, the capillary plexus of the median eminence was almost sufficiently reproduced; with this same injection, the capillary plexuses of the neural stalk and posterior lobe were only partially reproduced.

With an injection of 0.4 or $0.5 \mathrm{ml}$ resin, the capillary plexuses of the median eminence, neural stalk and posterior lobe were almost sufficiently reproduced, though some injection defects were occasionally noted in the neural stalk and posterior lobe (Figs. 4-7). With $0.4 \mathrm{ml}$ injection, original portions of the anterior, lateral and posterior long portal vessels were re-

Fig. 4. Ventral view of an incompletely replicated and isolated blood vascular bed of the adult rat hypophysis. This replica was prepared with a $0.4 \mathrm{ml}$ resin injection through the ascending aorta after ligation of thoracic aorta. Note that the capillary plexuses of the median eminence $(A M)$, neural stalk $(I S)$ and posterior lobe (IP) are reproduced, though some areas of the neural stalk and posterior lobe remain unfilled (asterisks). Also note that the long $(l p, r p)$ and short (cs, rs) portal vessels are partially reproduced. For other abbreviations, see Table 1. $\times 40$

Fig. 5. Ventral view of the incompletely replicated and isolated blood vascular bed of the adult rat hypophysis. This replica was prepared with $0.5 \mathrm{ml}$ resin injection. Note that the capillary plexuses of the median eminence $(A M)$ and posterior lobe $(I P)$ are reproduced together with the long $(r p, l p)$, short $(c s, l s, r s)$ and neurointermedial (thin arrowheads) portal vessels. Also note that the vascular plexus of the anterior lobe $(P D)$ is partially reproduced by the inflow of resin via the long portal vessels. Arrows indicate the ring-like constrictions imprinted in the anterior long portal vessels $(r p)$. Thick arrowheads indicate the branches of the middle hypophyseal arteries, especially the right one. Asterisk indicates the defective injection of resin in the posterior lobe $(I P)$. For other abbreviations, see Table $1 . \times 40$ 

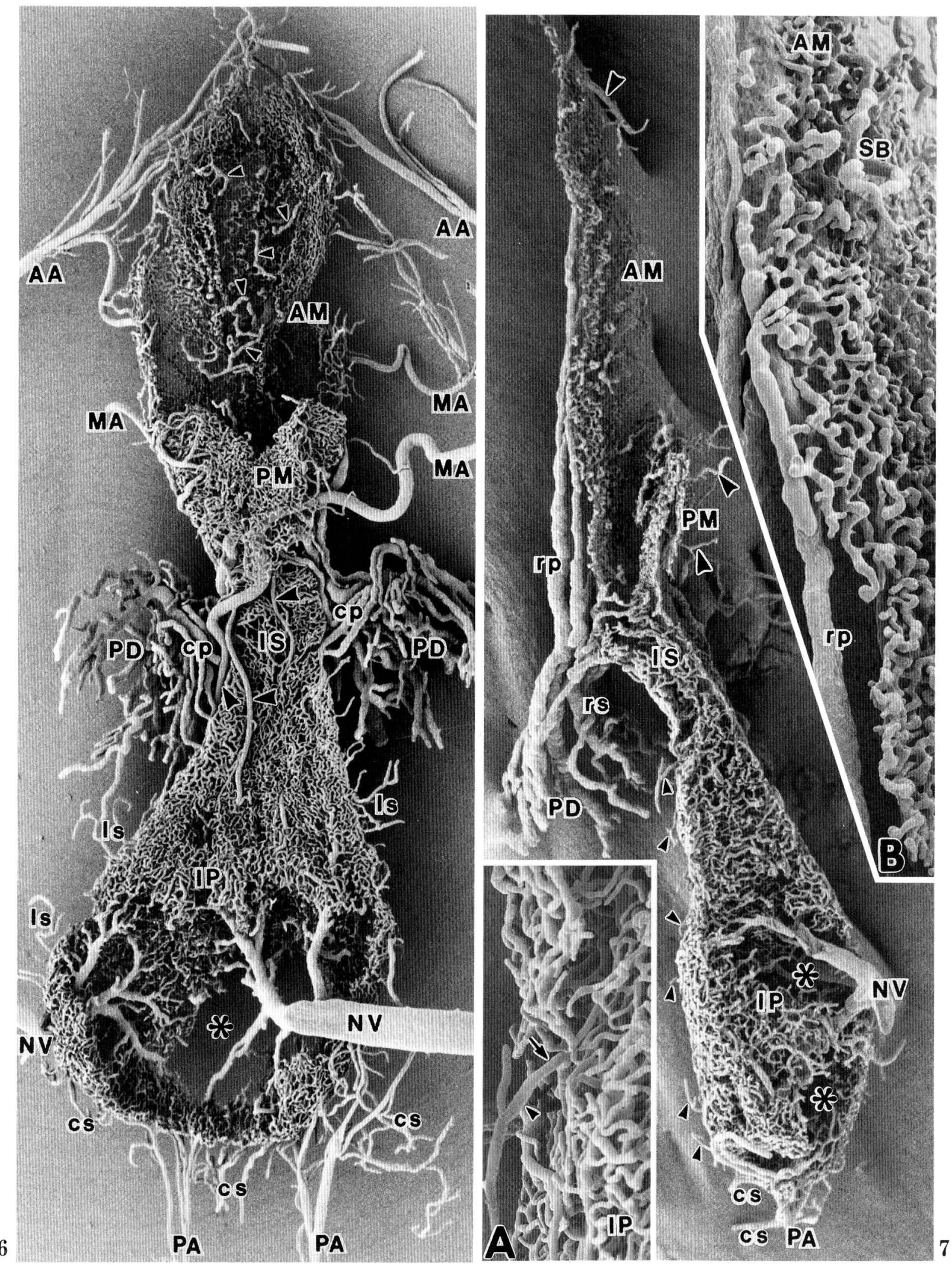

Figs. 6 and 7. Legends on the opposite page. 
produced; reproduction of the short portal vessels was only partial (Fig. 4). With $0.5 \mathrm{ml}$ resin injection, the reproduction of the capillary plexus of the anterior lobe began by the inflow of resin via long portal vessels (Figs. 5-7). The systemic emissary vein or veins of the posterior lobe (neurohypophyseal) were already reproduced with the 0.4 or $0.5 \mathrm{ml}$ resin injection (Figs. 4-6). The neuro-intermedial portal vessels were occasionally reproduced with the 0.4 or $0.5 \mathrm{ml}$ resin injections, though the capillary plexus of the intermediate lobe was never reproduced with these amounts (Fig. 7). Reproduction of the subependymal capillary plexus was possible first with the $0.5 \mathrm{ml}$ resin injection (Figs. 6, 7).

The greater the amount of resin injected, the more completely the hypophyseal capillary bed was reproduced. With an injection of 5.0 or $7.5 \mathrm{ml}$ resin, the capillary plexuses of the median eminence, subependyma, neural stalk, and posterior lobe were thoroughly reproduced, together with the long, accessory long (infundibular descending venules) and short portal vessels (Figs. 8-11).

The capillary plexus of the anterior lobe was always filled from the anterior and antero-dorsal aspects via the anterior, lateral and posterior long portal vessels; the anterior short portal vessels were sometimes well-developed and contributed toward filling the anterior lobe (Figs. 7, 10). Other portal vessels, including the posterior short portal vessels, contributed only in a small part to the filling of the capillary plexus of the anterior lobe. This was clearly noted in the cases of the 5.0 or $7.5 \mathrm{ml}$ resin injections (Figs. 8, 9). Portal drainage of the tuberal capillaries into the capillary plexus of the anterior lobe was also clearly replicated with these injections (Fig. 8).

The infundibular ascending veins originating in the subependymal plexus were partially reproduced with the 5.0 or $7.5 \mathrm{ml}$ resin injections (Fig. 10 Inset). The capillary plexus of the intermediate lobe was suffi- ciently reproduced with $10.0 \mathrm{ml}$ resin injection; with this same injection, however, the intermedio-distal portal vessels were not filled (Fig. 10). With the 10.0 $\mathrm{ml}$ resin injection, dorso-posterior portions of the posterior lobe were replicated mainly by the inflow of resin via the capillaries descending in the anterior lobe and additionally by the inflow of resin via the posterior short portal vessels (Fig. 10).

With an injection of 12.5 or $15.0 \mathrm{ml}$ resin, the capillary plexus of the intermediate lobe was almost sufficiently reproduced together with the intermediodistal portal vessels. Resin of $15.0 \mathrm{ml}$ thus clearly demonstrated the hypophyseal blood vascular plexuses, except for those in the ventro-posterior and latero-posterior portions of the anterior lobe (Fig. 11).

With the $20.0 \mathrm{ml}$ resin injection, as described above, all of the capillary plexuses and portal vessels were reproduced together with the systemic adenohypophyseal veins. Thus, the ventro-posterior and lateroposterior portions were the last to be replicated in the hypophyseal blood vascular bed with arterial resin injection.

Throughout the incomplete or $0.1-15.0 \mathrm{ml}$ resin injections, neither a retrograde resin flow from the capillary plexus of the anterior lobe to plexuses of the median eminence, neural stalk, and posterior lobe, nor a retrograde resin flow from there to the intermediate lobe and pars tuberalis was replicated. Similarly, neither a retrograde resin flow from the capillary plexus of the intermediate lobe to that of the posterior lobe, nor a retrograde resin flow from the capillary plexus of the intermediate lobe to that of the posterior lobe was replicated. Neither an ascending resin flow from the hypophyseal capillary plexuses, including those of the subependyma and median eminence, to the hypothalamic capillary beds, nor a descending resin flow from the hypothalamic capillary beds to the hypophyseal capillary plexuses was noted as well.

Fig. 6. Dorsal view of an incompletely replicated and isolated blood vascular bed of the adult rat hypophysis (the same specimen as shown in Figure 5). Note that the emissary veins ( $N V$ neurohypophyseal veins) of the posterior lobe $(I P)$ are filled entirely, though a large caudal portion of the posterior lobe remains unfilled (asterisk). Small arrowheads indicate the partially replicated subependymal capillary plexus. Large arrowheads indicate the branches of the right middle hypophyseal artery $(M A)$. For other abbreviations, see Table 1 . $\times 40$

Fig. 7. Incompletely replicated and sagittally freeze-cut blood vascular bed of the adult rat hypophysis. This replica was prepared with $0.5 \mathrm{ml}$ resin injection. Note that the capillary plexuses of the median eminence $(A M)$ and neural stalk $(I S)$ are sufficiently filled with resin, though some caudal portions of the posterior lobe (IP) remain unfilled (asterisks). Thick arrowheads indicate the partially infused infundibular ascending arterioles which penetrate the capillary plexus of the median eminence ( $A M$ anterior lip, PM posterior lip). Thin arrowheads indicate the partially replicated neuro-intermedial portal vessels. Inset A shows a closer view of the uppermost neuro-intermedial portal vessel (thin arrowhead). Inset B shows a closer view of a part of the median eminence. Note in the Inset $\mathbf{A}$ that the neuro-intermedial portal vessel (thin arrowhead) arises from the capillary plexus of the posterior lobe $(I P)$. Note in the Inset B that the subependymal capillary plexus $(S B)$ is incompletely injected with the $0.5 \mathrm{ml}$ resin injection. Arrow in Inset A indicates a ring-like constriction imprinted in the neuro-intermedial portal vessel. For other abbreviations, see Table $1 . \times 40$, Inset A: $\times 145$, Inset B: $\times 140$ 


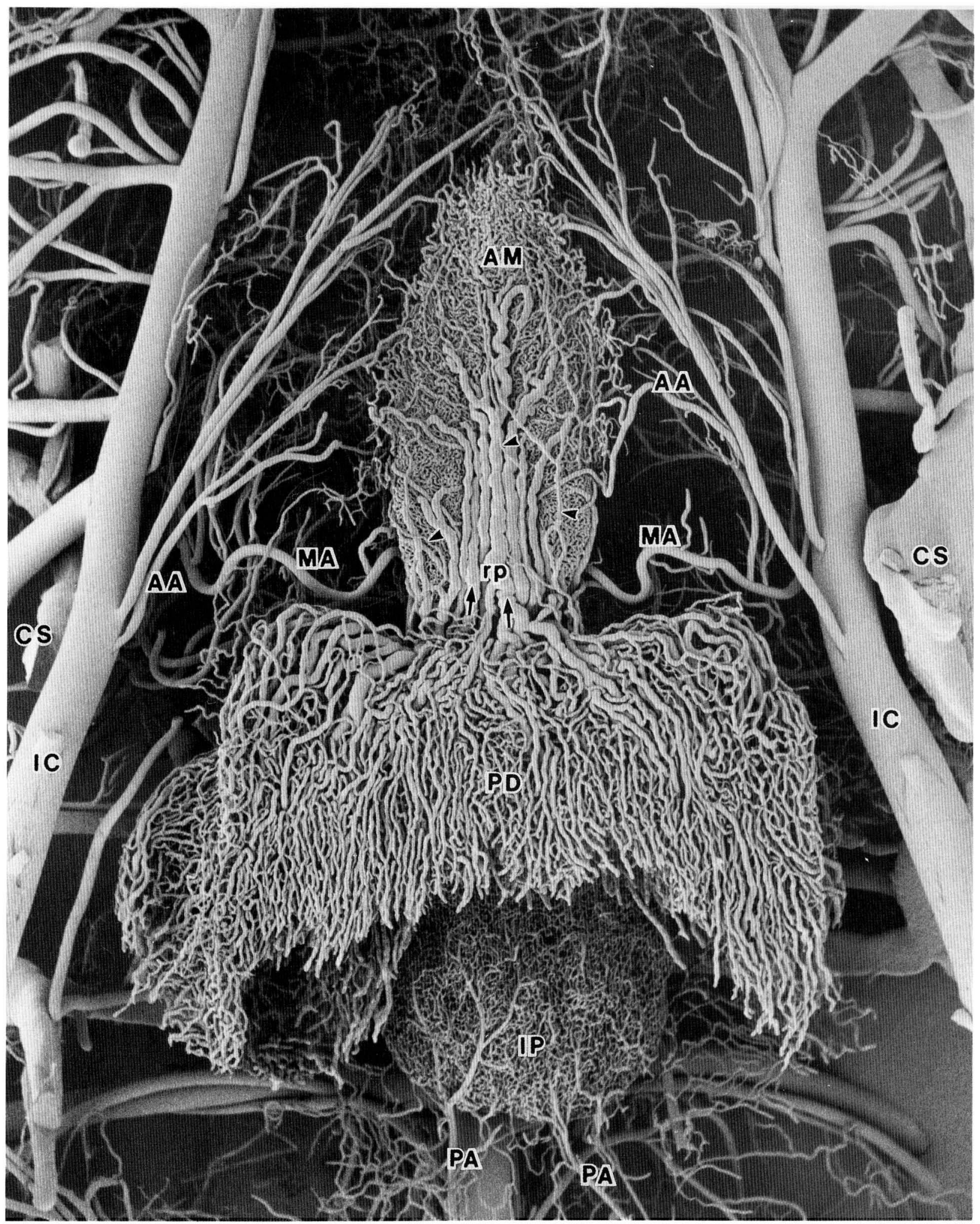

Fig. 8. Ventral view of an incompletely replicated blood vascular bed of the adult rat hypophysis. This replica was prepared with $7.5 \mathrm{ml}$ resin injection. Note that the capillary plexus of the anterior lobe $(P D)$ is mainly filled from the anterior and antero-dorsal aspects via the long portal vessels. Arrows indicate the ring-like constrictions imprinted in the anterior long portal vesels $(r p)$. Arrowheads indicate the tuberal capillaries. For other abbreviations, see Table $1 . \times 40$ 


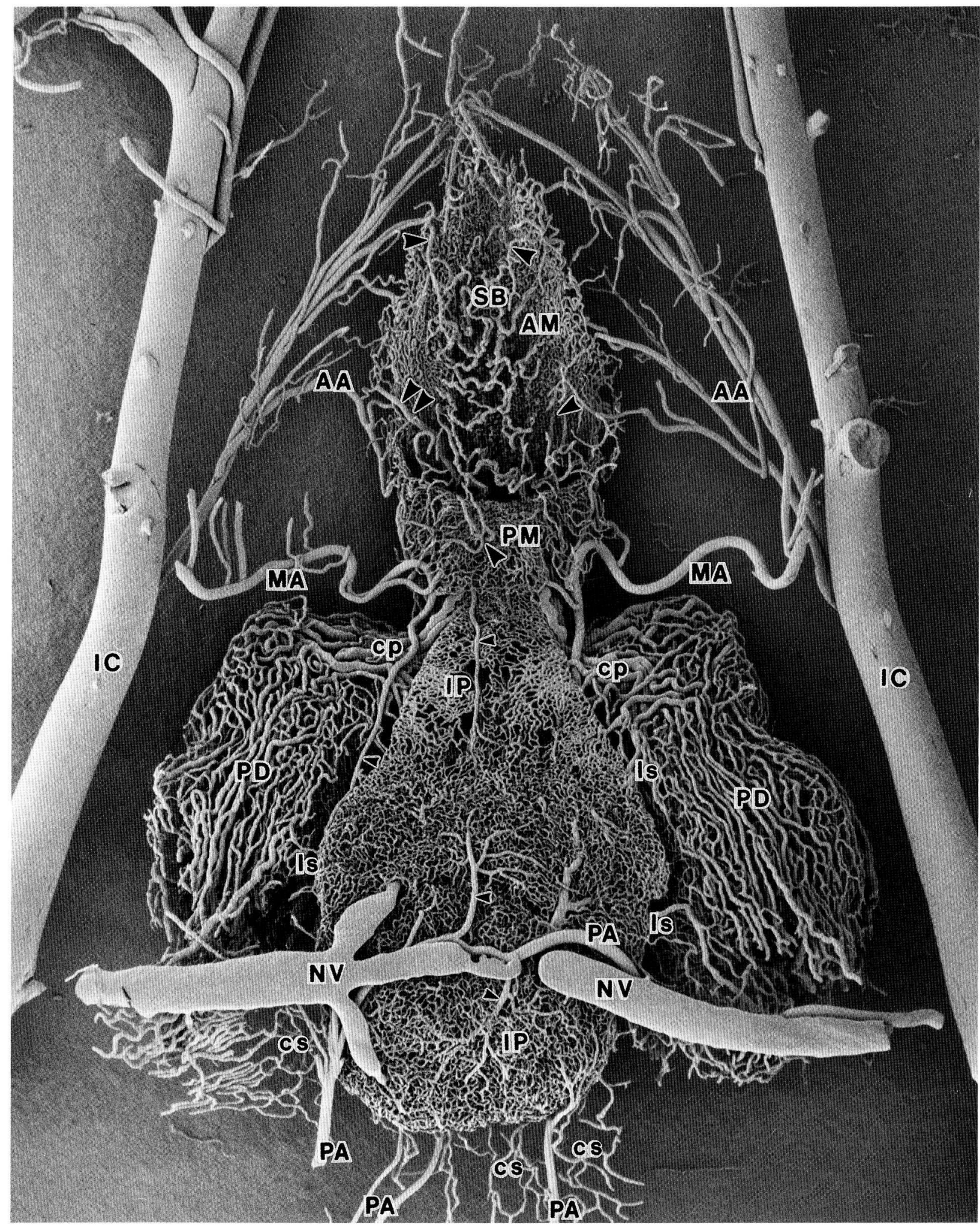

Fig. 9. Dorsal view of an incompletely replicated and isolated blood vascular bed of the adult rat hypophysis (the same specimen as shown in Figure 8 ). Note that the capillary plexuses of the median eminence ( $A M$ anterior lip, $P M$ posterior lip), subependyma $(S B)$, neural stalk and posterior lobe $(I P)$ are sufficiently reproduced together with the neurohypophyseal veins $(N V)$. Also note that, even at this stage of injection, the posterior portions of the anterior lobe $(P D)$ remain unfilled, though posterior short portal vessels $(c s)$ are reproduced almost sufficiently. Thick arrowheads indicate the partially infused infundibular ascending arterioles. For other abbreviations, see Table $1 . \times 40$ 


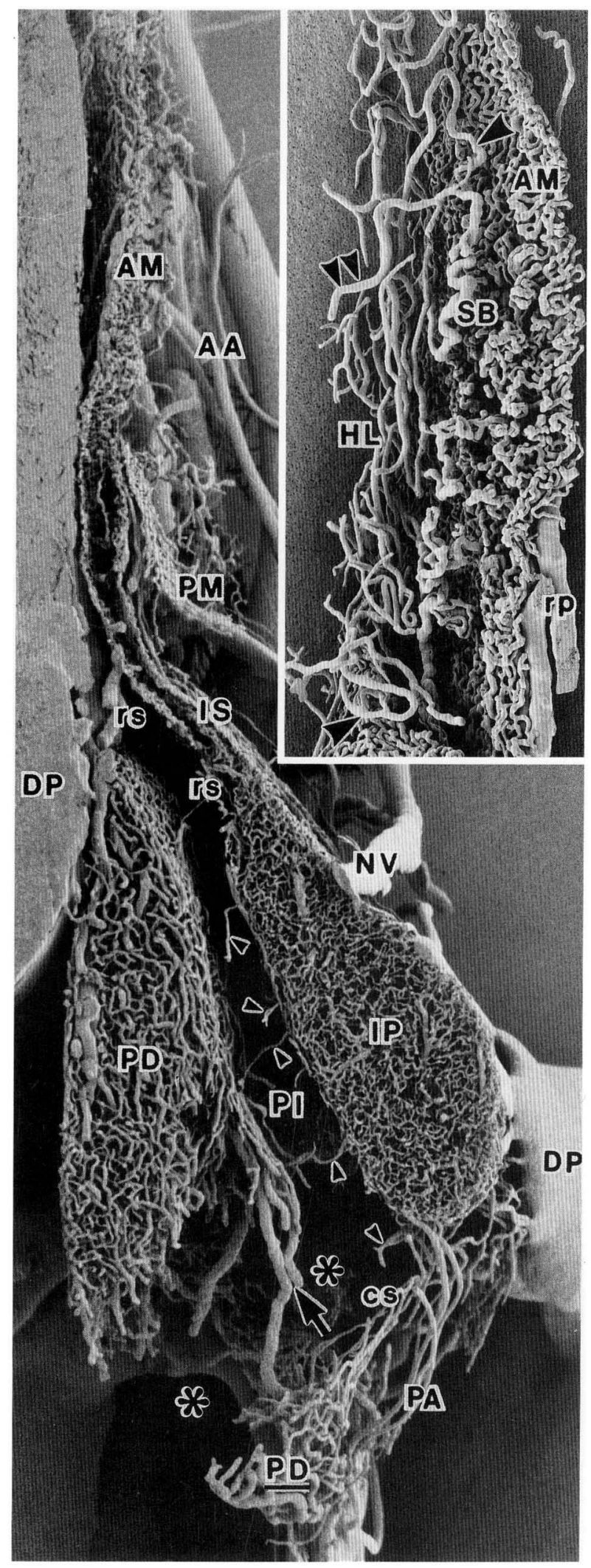

\section{Reproduction of the hypothalamic and other capil-} lary plexuses

As described above, $30.0 \mathrm{ml}$ or more resin was needed for a thorough reproduction of the hypothalamic and other cephalic capillary plexuses of the adult rat weighing $250-260 \mathrm{~g}$. However, the capillary plexuses of the paraventricular nucleus and mammillary body were sufficiently filled with $10.0 \mathrm{ml}$ resin (Fig. 12). Reproduction of the infundibular ascending arterioles penetrating the capillary plexus of the median eminence and ascending into the hypothalamus started to be filled with an injection of $0.5 \mathrm{ml}$ resin (Figs. 7, 9). However, 5.0 or more resin was needed for a thorough reproduction of the terminal capillary networks of these ascending arterioles (Fig. 10 Inset).

\section{Constrictions imprinted in the hypophyseal vascu- lar casts}

In both completely and incompletely injected cases, the origins of the anterior, middle and posterior hypophyseal arteries showed sharp and deep constrictions. Some shallow ring-like constrictions were imprinted in the long, accessory long and short portal vessels (Figs. 5, 8). Similar shallow ring-like constrictions were also noted even in such thin portal vessels as the neuro-intermedial portal vessels (Fig. 7 Inset A).

Fig. 10. Incompletely replicated and sagittally freezecut blood vascular bed of the adult rat hypophysis. This replica was prepared with $10.0 \mathrm{ml}$ resin injection. Note that some capillaries (arrow) in the middle portions of the anterior lobe $(P D)$ descend into the posterior portions $(\underline{P D})$ of the posterior lobe, and supply these portions $(\underline{P D})$ together with the posterior short portal vessels (cs). Also note that the dorso-posterior and ventro-posterior portions remain unfilled with the $10.0 \mathrm{ml}$ resin injection (aster$i s k s$ ). Inset shows a block of the replicated blood vascular plexuses of the median eminence $(A M)$, subependyma $(S B)$ and hypothalamus $(H L)$. This block was isolated from the replica prepared with the $10.0 \mathrm{ml}$ resin injection. Paired arrowheads indicate an infundibular ascending vein, which is partially injected via the subependymal capillary plexus $(S B)$. Thick arrowheads indicate the infundibular ascending arterioles. For other abbreviations, see Table $1 . \times 40$, Inset: $\times 70$ 


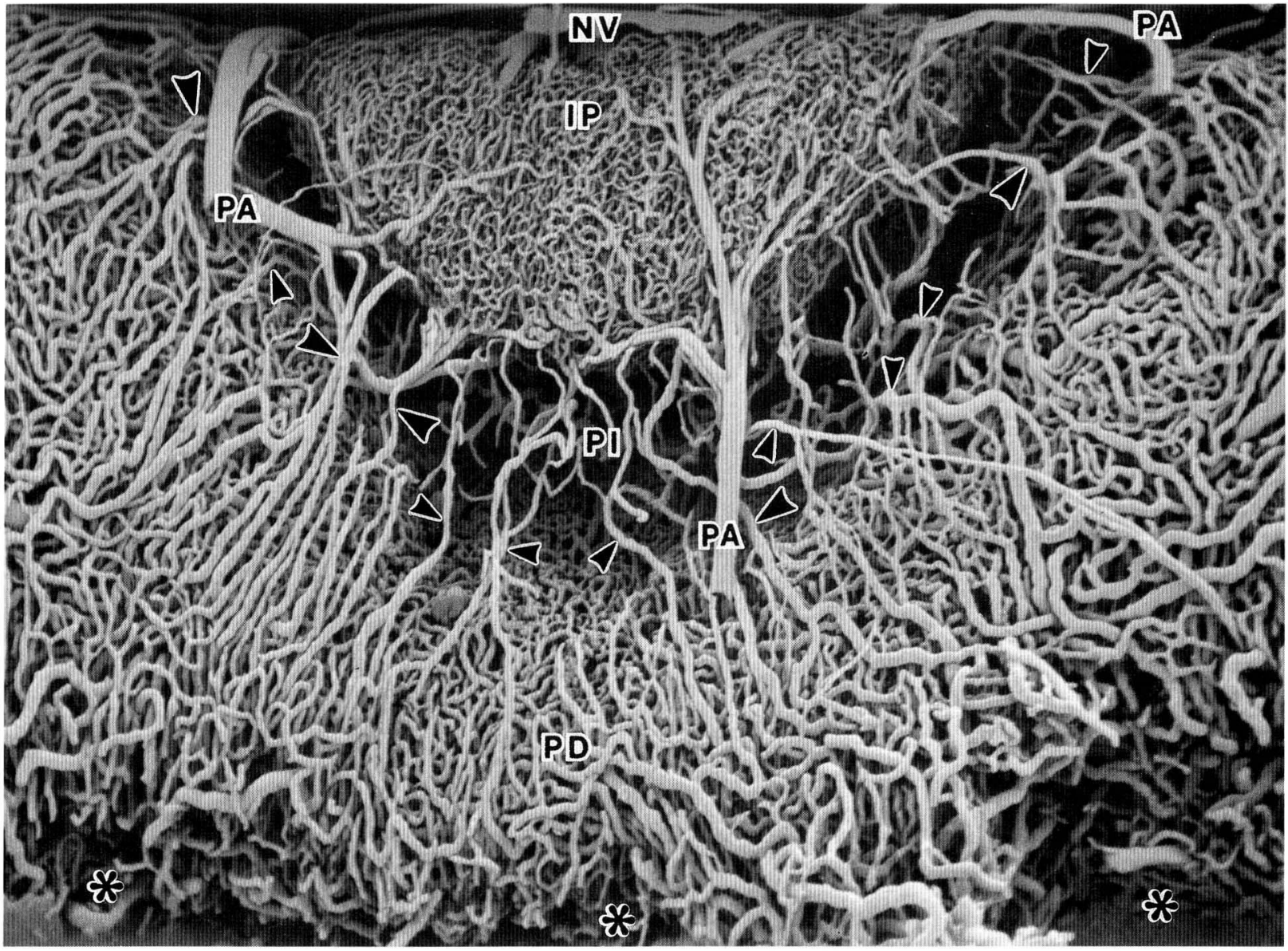

Fig. 11. Caudal view of the posterior end of the incompletely replicated and isolated blood vascular bed of the adult rat hypophysis. This replica was prepared with 15 . $0 \mathrm{ml}$ resin injection. Note that the capillary plexus of the intermediate lobe $(P I)$ has been almost entirely reproduced, though the ventro-posterior portions (asterisks) of the anterior lobe $(P D)$ still remain unfilled. Thick arrowheads indicate the posterior short portal vessels. Thin arrowheads indicate the posterior neuro-intermedial portal vessels. For other abbreviations, see Table $1 . \times 70$

Fig. 12. Dorsal view of incompletely replicated blood vascular beds of the adult rat hypothalamus and adjacent tissues. This replica was prepared with the $10.0 \mathrm{ml}$ resin injection, and freeze-cut horizontally at the level of the paraventricular nucleus $(P N)$ and mammillary body $(C M)$. Note that the capillary plexuses of the nucleus and body $(P N$ and $C M)$ are sufficiently reproduced, though those of the adjacent hypothalamic and other tissues are replicated incompletely. For other abbreviations, see Table $1 . \times 17$

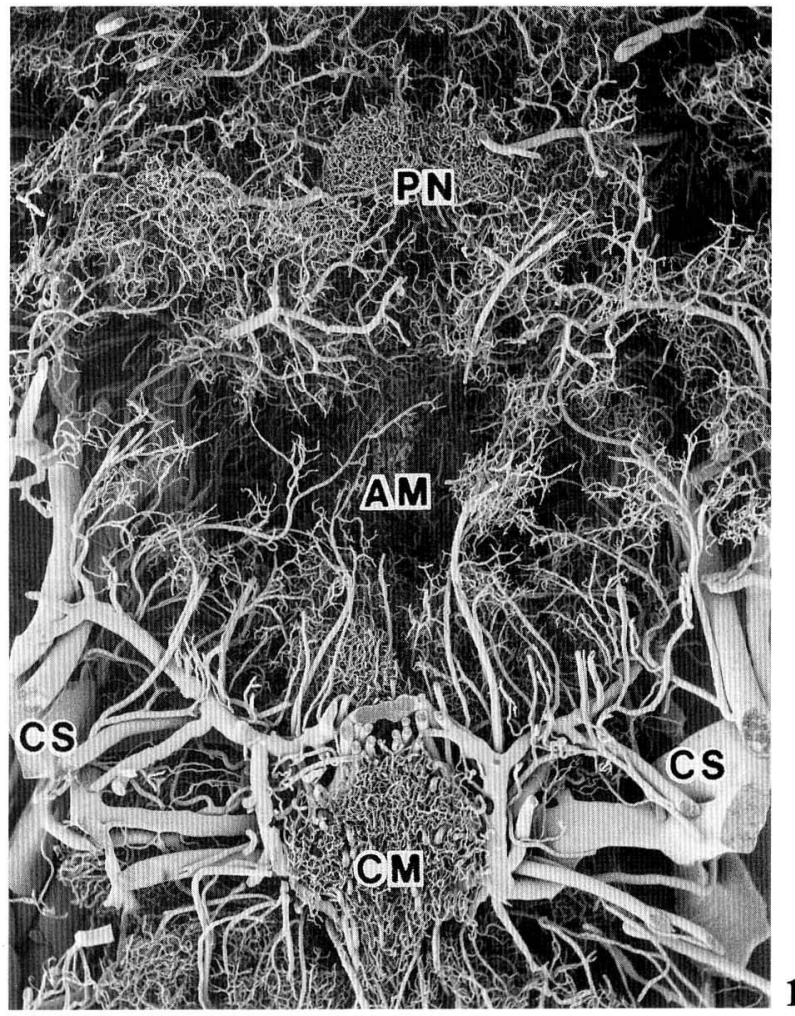




\section{DISCUSSION}

This paper, together with our previous studies of the kidney, pancreas, hypophysis and other organs in man, the monkey, the rat and other animals (MURAKAMI, 1971, 1992; FuJita and MuraKami, 1973; MURAKAMI et al., 1987, 1992; MURAKAMI and FUJITA, 1992), shows that complete replication of blood vascular beds allows a precise analysis of their structures under the scanning electron microscope. Together with our recent study of the rat pancreas (MIYAKE et al., 1992), the present study indicates that incomplete replication is useful to reveal the inflow modes of the casting medium into the blood vascular beds and also the outflow modes of the medium from the capillary beds into the veins, including the portal veins, as well as the running modes of the medium in the capillary beds.

Since our casting medium is as viscous as blood and perfused under physiological pressure, our vascular casts prepared by incomplete arterial injections properly reflect actual blood flow patterns, providing additional information to observations of the dynamic flow of blood (MURAKAMI et al., 1983; MIYAKE et al., 1992). Using this replication method, we have recently shown in the rat pancreas that a low viscosity casting medium fills blood capillaries in the endocrine pancreas more promptly than those in the exocrine lobules and secretory ducts, and that those lobules containing islets allow a more rapid resin flow through the insulo-acinar portal route than those lobules lacking an islet (MIYAKE et al., 1992).

In the hypophyseal and hypothalamic casts prepared here, it is noteworthy that the hypophyseal blood vascular bed is perfused more promptly than those of other tissue elements of the brain. This suggests that the hypophysis, including the median emience, is one of those organs which are most rapidly and richly supplied with blood. It is also noteworthy that the plexuses of the paraventricular nucleus and mammillary body are filled with the casting medium at a relatively early stage of injection. These structures are suggested to be also richly supplied with blood.

It is obscure as to who first described the hypophyseal portal system in any animal or by what method (DANDY and GOETSCH, 1911; POPA and FIELDING, 1930, 1933; BASIR, 1932; 'ESPINASSE, 1933; WISLOCKI, 1937, 1938; HARRIS, 1947a, b; GREEN, 1951, 1966; XUEREB et al., 1954; CHRIST, 1966; DANIEL, 1966; WINGSTRAND, 1966). However, many light microscopists have confirmed, mainly using India ink-injected tissue specimens, that this vascular system occurs throughout the vertebrates, becoming increasingly complicated with evolutionary order (WISLOCKI, 1937, 1938; HARRIS, 1947a, b; OfUJI, 1949; XUEREB et al., 1954; GREEN, 1951, 1966;
DANIEL and PRICHARD, 1957; GLYDON, 1957; LANDSMEER, 1957; TÖRÖK, 1954, 1960, 1964; ADAMS et al., 1964; Cummings and HaBel, 1965; Christ, 1966; Daniel, 1966; WingSTRAND, 1966; HolmES, 1967; NEGM, 1971; DUVERNOY, 1972; TERNEBY, 1972). Similar results have been obtained by modern workers, generally using the vascular casting and scanning electron microscope methods (MURAKAMI, 1975a, b; 1992; PAGE et al., 1976, 1978; LAMETSCHWANDTNER et al., 1977; PAINO et al., 1981; MURAKAMI et al., 1983, 1985, 1987; YosHIDA and IKUTA, 1984; HoNMA et al., 1987; GROSS et al., 1993).

The present scanning observation of completely replicated specimens, together with our previous ones (MURAKAMI, 1975a, 1992; MURAKAMI et al., 1985, 1987), discloses that the adult rat hypophyseal portal system consists of long, accessory long (subependymodistal), short, neuro-intermedial, intermedio-distal, and tuberalo-distal routes, and that the long route occupies the main part of the system. Our previous observations have also demonstrated in the rat that the long route is consistent throughout life, though other routes show some age-related or mating-related changes: 1) the plexus of the pars intermedia develops after puberty and forms the neuro-intermedial and intermedio-distal portal routes; 2) the plexus of the pars tuberalis develops after puberty and forms the tuberalo-distal portal route; 3) the short portal vessels are most conspicuous in the perinatal or neonatal periods (or at birth) and become markedly regressive after puberty; and 4) the capillary plexus of the intermediate lobe, its connecting neuro-intermedial and intermedio-distal portal vessels are most developed during mating or pregnancy (MURAKAMI et al., 1987; MURAKAMI, 1992).

The present scanning observation of incompletely replicated specimens indicates in the rat hypophysis that the blood flow in the long, accessory long, short, intermedio-distal, and tuberalo-distal routes is directed toward the anterior lobe, since the capillary plexuses of the median eminence, neural stalk, posterior lobe, tuberal lobe and intermediate lobe were fully replicated in much earlier stages of resin injection than the plexus of the anterior lobe. The blood flow in the neuro-intermedial portal route is suggested to be directed also toward the pars intermedia, since this route is filled with resin via the capillary plexus of the posterior lobe. The blood flow in the intermediodistal portal route presumably is directed toward the anterior lobe, since this route is filled with resin via the capillary plexus of the intermediate lobe.

The present scanning observation of incompletely replicated specimens shows that the capillary plexuses of the median eminence, neural stalk and posterior lobe are replicated almost entirely at the earliest stages of arterial resin injection, and that the capillary plexus of the median eminence is more promptly 


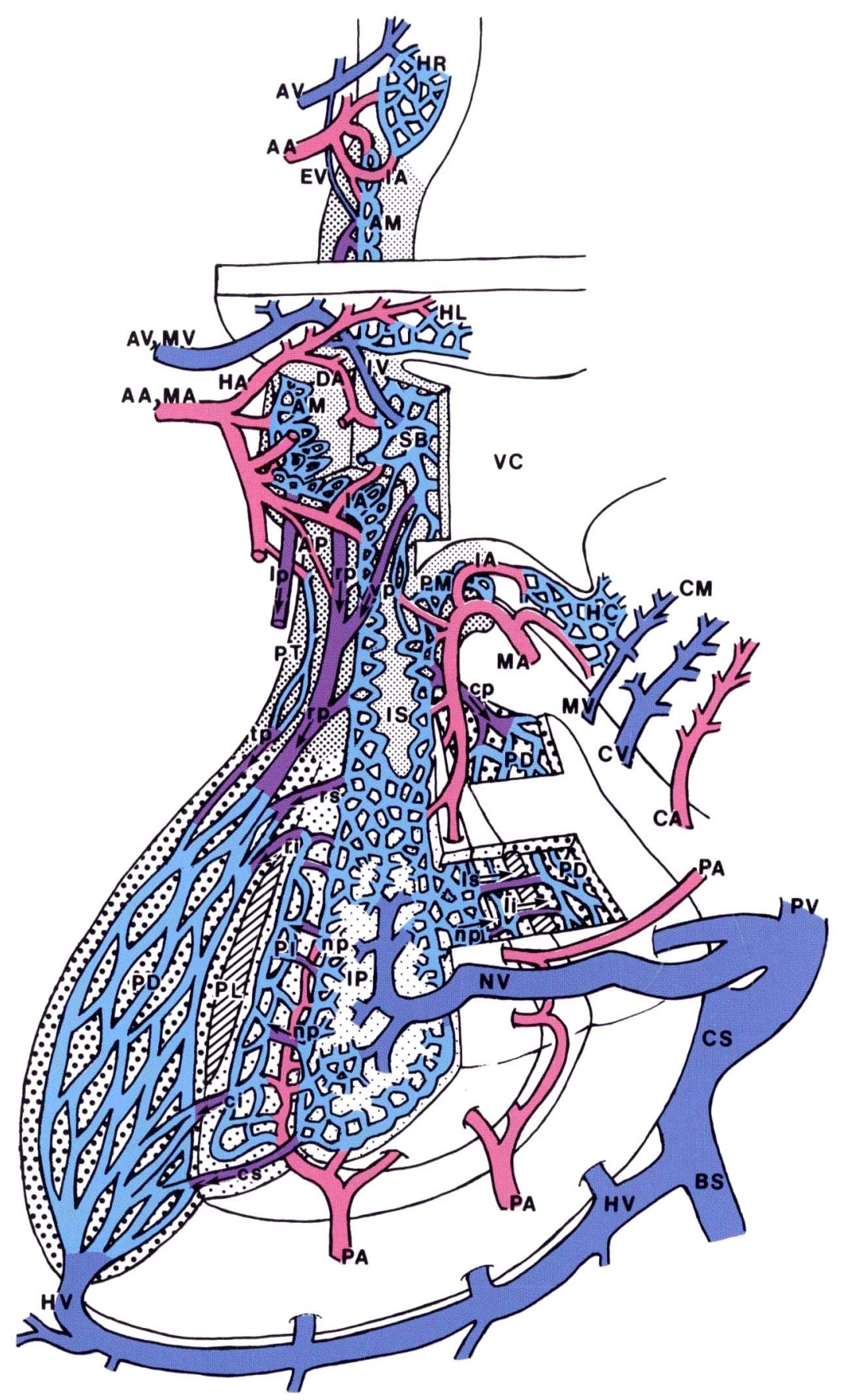

Fig. 13. Diagram showing the vascular arrangements of the adult rat hypophysis and hypothalamus (modified after Murakami et al., 1987). Arrows indicate the directions of resin flow in the portal vessels, which are demonstrated in the present study. These microcirculatory modes or directions suggest those of the physiological blood flow in the portal vessels, since the resin medium used was as viscous as blood and injected under physiological pressure (see text). For abbreviations, see Table 1 
replicated than the vascular beds of the neural stalk and posterior lobe. These findings indicate that the median eminence is the most richly supplied with arterial blood.

Blood leakage from the capillary plexus of the median eminence into the systemic veins may be negligible since the systemic emissary veins of the median eminence are small in size and filled with resin at a later stage of injection. Blood leakage from the subependymal capillary plexus into the systemic veins may also be negligible, because the infundibular ascending veins are also small in size and filled with resin at a later stage of injection. We therefore believe that the blood in the subependyma, median eminence and neural stalk preferentially flows into the anterior lobe.

The present scanning observation of incompletely replicated specimens further shows that the neurohypophyseal vein or veins are large in size and promptly filled with the injected resin at the earliest stages of resin injection, and that the short portal vessels and neuro-intermedial portal vessels are small in size and not so large in number. These facts indicate that the blood in the posterior lobe preferentially flows into the systemic veins via the neurohypophyseal veins, and that only a small amount of the blood in the posterior lobe flows into the anterior lobe via the short portal vessels and into the intermediate lobe via the neuro-intermedial portal vessels. As introduced above, however, the short portal vessels are well developed in the prenatal and postnatal rats; the neuro-intermedial and intermedio-distal portal vessels and their connecting capillary plexus of the intermediate lobe become conspicuous in pubescent rats (MURAKAMI et al., 1987; MURAKAMI, 1992). In growing or mating rats, a considerable amount of blood may flow from the posterior lobe into the anterior lobe, either directly via the short portal route or indirectly via the neuro-intermedial and intermedio-distal portal routes (MURAKAMI et al., 1987; MURAKAMI, 1992). We believe that such conspicuously developed short portal vessels in the growing (perinatal or neonatal) rats must bear a special functional significance in that they convey hypothalamic hormones (especially, the growth hormone-releasing factor), leaking into the posterior lobe to the anterior lobe (MURAKAMI et al., 1987; Murakami, 1992). We also believe that the well developed neuro-intermedial and intermediodistal portal routes, especially the latter, absorb the colloid in the hypophyseal cleft and convey it to the anterior lobe in mating or pregnant rats (MURAKAMI et al., 1985; MURAKAMI, 1992).

Immunoassay studies in the rat have detected the hypophyseal hormones, including MSH and oxytocin, in the blood of long portal vessels, and suggested that the blood in the capillary plexuses of the anterior and posterior lobes can return to the median eminence (Oliver et al., 1977; GiBBS, 1984; HorN et al., 1985; KNEPEL, 1987). Some authors, who mainly observed completely replicated vascular samples of the monkey, the rat and other animals with a scanning electron microscope, proposed that blood within the hypophysis might be "circular"; in other words, an interlobar blood flow may occur in either direction, a condition that seems possible in such portal vessels which must have low luminal pressure permitting backflow under certain physiological conditions (PAGE et al., 1976; BERGLAND and PAGE, 1978, 1979; OHTANI, 1981; PAGE, 1982, MEZEY and PALKovits, 1982). Others have considered, as introduced by Gross et al. (1993), that the short portal vessels are the first irrigation channels to provide blood flow from the anterior lobe to the posterior lobe and neural stalk (TöRöK, 1954, 1964; SZENTÁGOTHAI et al., 1968). In this case, then, blood might subsequently pass in a retrograde manner from the posterior lobe into the median eminence, third ventricular subependyma and hypothalamus (PAGE, 1982). Furthermore, GROSS et al. (1993) observed completely replicated rat samples with a scanning microscope and contended that the short portal route provides a constant stream of neurohumoral information that is shared moment by moment between the posterior and anterior lobes. However, no evidence supporting this circular or retrograde circulation premise has been obtained by the present incomplete arterial replication method using resin with viscosity as low as blood together with physiological injection pressure.

Certain authors have observed carmine gelatine- or India ink-injected tissues of the dog, rat and other animals with a light microscope, and recorded many ascending portal vessels which arose from the capillary plexuses of the median eminence, neural stalk and posterior lobe and continued into the capillary bed of the hypothalamus (BASIR, 1932; OFUJI, 1949; TÖRÖK, 1960, 1964). PAGE and his associates also demonstrated, by scanning electron microscopy of vascular casts of the monkey, rat and other animals, how numerous capillaries or fine vessels connected the capillary plexuses of the median eminence and infundibular stalk to the hypothalamic capillaries (PAGE et al., 1978; Bergland and PAGE, 1979). However, we have not observed such capillaries or ascending portal vessels, except for infundibular ascending and descending arterioles and for the infundibular ascending and descending venules (MURAKAMI et al., 1975a, 1987). Even in the present study using the incomplete and complete arterial injection methods, no portal vessel was recognizable which ascended from the hypophyseal capillary plexuses, including those of median eminence and subependyma, to the capillary bed of the hypothalamus. Neither was re- 
plicated a descending portal vessel from the hypothalamus to the hypophysis. These findings coincide with our previous results obtained from completely replicated specimens (MURAKAMI et al., 1975a, 1987).

The sharp and deep constrictions imprinted at the origins of the anterior, middle and posterior hypophyseal arteries suggest the occurrence of endothelial arterial cushions at these sites, possibly inhibiting a backflow of blood (MURAKAMI et al., 1987). The shallow ring-like constrictions imprinted in the long and other portal vessels, including the intermedio-distal portal vessels, suggest the occurrence of sphincter muscles in these vessels (MURAKAMI et al., 1987).

\section{REFERENCES}

Adams, J. H., P. M. Daniel and M. M. L. Prichard: Distribution of hypophysial portal blood in the anterior lobe of the pituitary gland. Endocrinology 75: 120-126 (1964).

BASIR, M. A.: The vascular supply of the pituitary body in the dog. J. Anat. 66: 387-398 (1932).

Bergland, R. M. and R. B. Page: Can pituitary secrete directly to the brain? Affirmative anatomical evidence. Endocrinology 102: 1325-1338 (1978).

Bergland, P. M. and R. B. PAge: Pituitary-brain vascular relations: a new paradigm. Science 204: 18-24 (1979).

Christ, J. F.: Nerve supply, blood supply and cytology of the neurohypophysis. In: (ed. by) G. W. HARRIS and B. T. Donovan: The pituitary gland. Vol. 3. Pars intermedia and neurohypophysis. Butterworths, London, 1966 (p. 62-130).

Cummings, J. F. and R. E. Habel: The blood supply of the bovine hypophysis. Amer. J. Anat. 116: 91-114 (1965).

Dandy, W. E. and E. Goetsch: The blood supply of the pituitary body. Amer. J. Anat. 11: 137-150 (1911).

DANIEL, P. M.: The anatomy of the hypothalamus and pituitary gland. In: (ed. by) L. MARTINI and W. F. GANONG: Neuroendocrinology, Vol. 1. Academic Press, New York and London, 1966 (p. 15-80).

Daniel. P. M. and M. M. L. Prichard: The vascular arrangements of the pituitary gland of the sheep. Quart. J. Exp. Physiol. 42: 237-248 (1957).

DUVERNOY, H.: The vascular architecture of the median eminence. In: (ed. by) K. M. KNIGGE, D. E. ScotT and A. WEINDL: Brain-endocrine interaction. Median eminence. Structure and function (Int. Symp. Munichi 1971). Karger, Basel, 1972 (p. 79-108).

'Espinasse, P. G.: The development of the hypophysioportal system in man. J. Anat. 68: 11-18 (1933).

Fujita, T. and T. Murakami: Microcirculation of monkey pancreas with special reference to the insulo-acinar portal system. A scanning electron microscope study of vascular casts. Arch. Histol. Jap. 35: 255-263 (1973).

GiBBS, D. M.: High concentration of oxytocin in hypophyseal portal plasma. Endocrinology 114: 1216-1218 (1984).
GLYdon, R. ST. J.: The development of the blood supply of the pituitary in the albino rat, with reference to the portal vessels. J. Anat. 91: 237-244 (1957).

Green, J. D.: The comparative anatomy of the hypophysis with special reference to its local blood supply and innervation. Amer. J. Anat. 88: 225-312 (1951).

- : The comparative anatomy of the portal vascular system and of the innervation of the hypophysis. In: (ed. by) G. W. HARris and B. T. DonOvan: The pituitary gland. Vol. 1. Anterior pituitary. Butterworths, London, 1966 (p. 127-146).

Gross, P. M., M. G. Joneja, J. J. Pang, T. M. Poli SChUK, S. W. Shaver and D. S. Wainman: Topography of short portal vessels in the rat pituitary gland: a scanning electron-microscopic and morphometric study of corrosion cast replicas. Cell Tiss. Res. 272: 79-88 (1993).

HARRIS, G. W.: The hypophysio-portal vessels of the porpoise (Phocaena phocaena). Nature 159: 874-875 (1947a).

- The blood vessels of the rabbit's pituitary gland, and significance of the pars and zona tuberalis. J. Anat. 81: 343-351 (1947b).

Holmes, R. L.: The vascular pattern of the median eminence of the hypophysis in macaque. Fol. Primat. 7: 216-230 (1967).

Honma, Y., Y. Toda and A. Chiba: Vascularization of the hypothalamo-hypophysial complex in Japanese elasmobranchs: a scanning electron microscope study of blood vascular casts. Arch. Histol. Jap. 50: 39-48 (1987).

HoRn, A. M., I. C. A. F. Robinson and G. Fink: Oxytocin and vasopressin in rat hypophysial portal blood, experimental studies in normal and Brattleboro rats. J. Endocrinol. 104: 211-224 (1985).

KNEPEL, W.: Anterior pituitary hormones and vasopressin release. In: (ed. by) P. M. GRoss: Circumventricular organs and body fluids, Vol. II. CRC Press, Boca Raton, 1987 (p. 109-135).

Lametschwandtner, A., P. Simonsberger and H. Adam: Vascularization of the pars distalis of the hypophysis in the toad, Bufo bufo (L.) (Amphibia, Anura). A comparative light microscopical and scanning electron microscopical study. Cell Tiss. Res. 179: 1-10 (1977).

LANDSMEeR, J. M. F.: Vessels of the rat's hypophysis. Acta Anat. 12: 82-109 (1957).

Mezey, E. and M. Palkovits: Two-way transport in the hypothalamo-hypophysial system. Front. Neuroendocrinol. 7: 1-29 (1982).

Miyake, T., T. Murakami and A. Ohtsuka: Incomplete vascular casting for a scanning electron microscope study of the microcirculatory patterns in the rat pancreas. Arch. Histol. Cytol. 55: 397-406 (1992).

MURAKami, T.: Application of the scanning electron microscope to the study of the fine distribution of the blood vessels. Arch. Histol. Jap. 32: 445-454 (1971).

: Pliable methacrylate casts of blood vessels: use in a scanning electron microscope study of the microcirculation in rat hypophysis. Arch. Histol. Jap. 38: 151168 (1975a).

: Injection replica scanning electron microscope method for studying the fine distribution of the blood 
vessels (In Japanese). The Cell (Tokyo) 7: 11-18 (1975b).

Murakami, T.: Organization and age-related changes of the rat hypophyseal blood vascular plexuses and portal vessels as observed by the injection replica SEM method. In: (ed. by) P. M. MotTA, T. MurakAMI and H. FUJITA: Scanning electron microscopy of vascular casts: methods and applications. Kluwer Academic Publishers, Boston/Dordrecht/London, 1992 (205-220).

Murakami, T. and T. Fujita: Microcirculation of the rat pancreas, with special reference to the insulo-acinar portal and insulo-venous drainage systems: a further scanning electron microscope study of corrosion casts. Arch. Histol. Cytol. 55: 453-476 (1992).

Murakami, T., M. Unehira, H. KaWakami and A. KuBotsu : Osmium impregnation of methyl methacrylate vascular casts for scanning electron microscopy. Arch. Histol. Jap. 36: 119-124 (1973).

Murakami, T., O. Ohtani, A. Ohtsuka and A. Kikuta: Injection replication and scanning electron microscopy of blood vessels. In: (ed. by) G. M. HodGEs and K. E. CARR: Biomedical research applications of scanning electron microscopy, Vol. 3. Academic Press, London, 1983 (p. 1-30).

Murakami, T., A. Ohtsuka, T. Taguchi, A. Kikuta and O. Ohtani: Blood vascular bed of the rat pituitary intermediate lobe, with special reference to its development and portal drainage into the anterior lobe. A scanning electron microscope study of vascular casts. Arch. Histol. Jap. 48: 69-87 (1985).

Murakami, T., A. KikUta, T. Taguchi, A. Ohtsuka and 0. Ohtani: Blood vascular architecture of the rat cerebral hypophysis and hypothalamus. A dissection/ scanning electron microscopy of vascular casts. Arch. Hitol. Jap. 50: 133-176 (1987).

Murakami, T., T. Fujita and H. Hinenoya: A modified method for vascular casting and scanning electron microscopy: its utility in the demonstration of rat pancreatic insulo-acinar and other blood vascular systems. Arch. Histol. Cytol. 55: 233-238 (1992).

NEGM, I. M.: The blood supply of the mouse hypophysis cerebri. Acta Anat. 80: 377-387 (1971).

OFUJ, T.: Vascular architecture of the mouse hypothalamus and hypophysis. III. Hypophyseal portal system (In Japanese). Okayama Igakkai Zasshi 61: 207-217 (1949).

OHtani, 0.: Microcirculation studies by the injectionreplica method with special reference to the portal circulation. In: (ed. by) L. J. A. DiDio, P. M. MotTA, D. J. AllEN: Three dimensional microanatomy of cells and tissues. Elsevier, New York, 1981 (p. 51-70).

Oliver, C., R. S. MiCAL and J. C. PorTer: Hypothalamicpituitary vasculature: evidence for retrograde blood flow in the pituitary stalk. Endocrinology 101: 598-604 (1977).

Page, R. B.: Pituitary blood flow. Amer. J. Physiol. 243: E427-442 (1982).

Page. R. B., B. L. Munger and P. M. Bergland: Scanning microscopy of pituitary vascular casts. Amer. J. Anat. 146: 273-302 (1976).
Page, R. B., A. E. Leure-DuPree and R. M. Bergland: The neurohypophyseal capillary bed. II. Specialization within median eminence. Amer. J. Anat. 153: 33-66 (1978).

Paino, G., M. Langella and G. Caputo: Vascular feature of the hypophysis in Bulbalus buffelus. Acta Anat. 110: 206-218 (1981).

PoPA, G. and U. Fielding: A portal circulation from the pituitary to the hypothalamic region. J. Anat. 65: 88-91 (1930).

- Hypophysis portal vessels and their colloid accompaniment. J. Anat. 67: 227-232 (1933).

Szentágothai, J., B. Flerkó, B. Mess and B. Halāsz: Hypothalamic control of the anterior pituitary. An experimental-morphological study. Akadémiai Kiadó, Budapest, 1968. (p. 81-109).

Terneby, U.: The development of hypophysial drainage in the rabbit. Z. Anat. Entw.-Gesch. 136: 294-310 (1972).

TöRök, B.: Lebensbeobachtung des Hypophysenkreislaufs an Hunden. Acta Morphol. Acad. Sci. Hung. 4: 8389 (1954).

- : Neue Angaben zum Blutkreislauf der Hypophyse. Verh. Anat. Anz. 109: 622-629 (1960).

: Structure of the vascular connections of the hypothalamo-hypophysial region. Acta Anat. 59: 84-99 (1964).

Wingstrand, K. G.: Microscopic anatomy, nerve supply and blood supply of the pars intermedia. In: (ed. by) G. W. HARRIS and B. T. DONOVAN: The pituitary gland. Vol. 3. Pars intermedia and neurohypophysis. Butterworths, London, 1966 (p. 1-27).

WISLOCKI, G. B.: The vascular supply of the hypophysis cerebri of the cat. Anat. Rec. 69: 361-387 (1937).

WISLOCKI, G. B.: The vascular supply of the hypophysis cerebri of the rhesus monkey and man. Res. Publ. Assoc. Res. Nerv. Ment. Dis. 17: 48-68 (1938).

Xuereb, G. P., M. M. I. Prichard and P. M. Daniel: The hypophysial portal system of vessels in man. Quart. J. Exp. Physiol. 39: 219-230 (1954).

Yoshida, Y. and F. IkUta: Three-dimensional architecture of cerebral microvessels with a scanning electron microscope: a cerebrovascular casting method for fetal and adult rats. J. Cereb. Blood Flow Metab. 4: 290-296 (1984).

Prof. Takuro MuRAKAMI

Section of Human Morphology

Department of Anatomy

Okayama University School of Medicine

2-5-1 Shikata-cho

Okayama, 700 Japan

村上 宅 郎

700 岡山市鹿田町 2-5-1

岡山大学医学部

解剖学第二講座 